\title{
Review Article \\ Biogenesis and Biological Activity of Secondary siRNAs in Plants
}

\author{
Franck Vazquez and Thomas Hohn \\ Institute of Botany, University of Basel, Zürich-Basel Plant Science Center, Part of the Swiss Plant Science Web, \\ CH-4056 Basel, Switzerland \\ Correspondence should be addressed to Franck Vazquez; franck.vazquez@unibas.ch
}

Received 30 October 2012; Accepted 6 December 2012

Academic Editors: A. P. Malykhina, H. Schatten, and M. Wassenegger

Copyright (C) 2013 F. Vazquez and T. Hohn. This is an open access article distributed under the Creative Commons Attribution License, which permits unrestricted use, distribution, and reproduction in any medium, provided the original work is properly cited.

Two important hallmarks of RNA silencing in plants are (1) its ability to self-amplify by using a mechanism called transitivity and (2) its ability to spread locally and systemically through the entire plant. Crucial advances have been made in recent years in understanding the molecular mechanisms of these phenomena. We review here these recent findings, and we highlight the recently identified endogenous small RNAs that use these advantageous properties to act either as patterning signals in important developmental programs or as a part of regulatory cascades.

\section{Introduction}

RNA silencing is a recently identified mechanism important for the transcriptional and posttranscriptional control of genes and genomes in eukaryotes [1-4]. It also contributes to the defence against viruses [5-10], viroids [11, 12], transposons [13], foreign nucleic acids (e.g., transgenes) [14], and in some cases even against micro-organisms $[10,15,16]$.

RNA silencing involves processing of dsRNA by DICERs or DICER-LIKEs to produce small RNA (sRNA) duplexes, capture of the guide siRNA strand by ARGONAUTE (AGO) proteins to form RNA-induced silencing complexes (RISCs) and recognition of homologous target DNA or RNA sequences by RISCs [17-19].

In plants, four endogenous pathways, characterized in Arabidopsis thaliana by four specific DICER-LIKE enzymes (DCLs), are involved in sRNA, that is, small interfering (si)RNA and micro (mi)RNA, production [20] (Figure 1). In the RNA-dependent DNA methylation (RdDM) pathway, DCL3 produces $24 \mathrm{nt}$ long siRNAs to establish transcriptional gene silencing $[21,22]$. This primary $\mathrm{RdDM}$ step is further supported by a secondary sRNA-generating machinery that includes RNA polymerases IV and V, AGO4, RNAdependent RNA polymerase (RDR)2, chromatin remodelling proteins and DNA, and histone methylases [23].

DCL4, together with RDR6 (RNA-dependent RNA polymerase 6), SGS3 (SUPPRESSOR OF GENE SILENCING 3), and DRB4 (dsRNA BINDING PROTEIN 4), produces 21nt long trans-acting (ta-) siRNAs from TAS RNA precursors and other types of RNAs [24-28]. DCL2 generates low abundant 22nt long siRNAs from different precursors and mainly acts as a surrogate when DCL4 or DCL3 is mutated or suppressed [29-33]. DCL2 also has a major role in transitivity (discussed in the following) [14]. DCL1 generates 21-22nt miRNAs, and DCL3 generates 23-24nt long-miRNAs from bulged hairpins formed within pri-miRNAs [31, 34-36]. DCL2, DCL3, and DCL4 are also able to generate siRNAs from long hairpins [31,37]. Silencing by RISC complexes with miRNAs or 21 and 22nt siRNAs can occur by two types of activities. The recognized target RNA is either cleaved (sliced) or its translation is inhibited [38-44]. A clear rule determining one or the other of these alternatives has not yet been identified in each case, although it was suggested in earlier works that slicing is favoured when the complementarity between sRNA and target is perfect or near perfect, while translation inhibition is favoured when the complementarity is imperfect. Because both types of regulations have been reported for a given sRNA/target pair, it is possible that the decision on which mechanism to use depends on specific genetic programming of the different cell types [38, 42, 45].

While DCLs have specific roles in the regulation of genome expression and maintenance, they are all involved in the defence against viruses $[8,17,64]$. For Cauliflower mosaic Caulimovirus (CaMV) and Cabbage leaf curl Begomovirus 


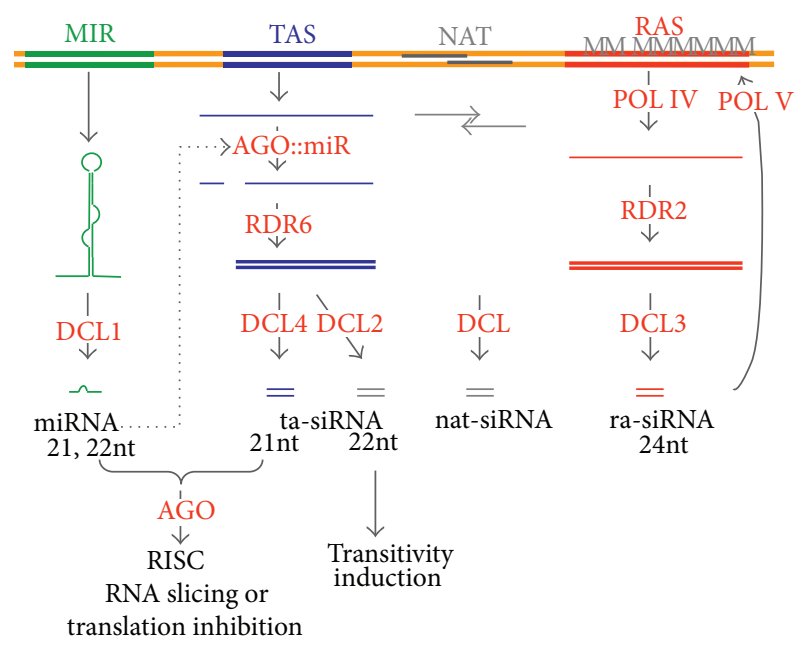

Figure 1: Posttranscriptional and transcriptional gene silencing pathways. Pri-miRNAs consist of a bulged hairpin flanked by unstructured arms. They are transcribed from the relevant MIR genes and are processed predominantly by the DCL1 "Drosha activity" and further by the DCL1 "Dicer activity," yielding a miRNA duplex. Before processing, the pri-miRNAs, which can be extremely long, are spliced [46]. The DCL1 cofactor, the double-stranded RNA binding protein HYL1, and the 2'-OH ds RNA methyl transferases HEN1, SERRATE, or DAWDLE are not shown [34, 47-51]. Methylation by HEN1serves to protect the miRNA duplex from uridylation and degradation by SDN nucleases [52-57]. With miRNA guide strand and AGO1, a RISC is formed [58, 59], which binds to the cognate target and either slices it or arrests its translation. This step involves the function of cyclophilin 40 and HSP90 [60, 61]. TAS RNAs are transcribed from specific genes too, namely, the TAS genes. TAS RNAs are originally capped and polyadenylated, but they loose the cap and mostly also the poly-A end upon miRNA guided cleavage. They then become processed mainly by DCL4 in a phased way to generate secondary siRNAs, termed ta-siRNAs, which control target mRNAs, similarly as miRNAs $[19,62]$. Nat-siRNAs are produced from overlapping dsRNA regions formed by natural antisense transcripts (NATs). Repeat-associated sequences (RASs) give rise to $24 \mathrm{nt}$ long ra-siRNAs through the action of DCL3. rasiRNAs are amplified by POL IV and RDR2 and are involved in DNA and histone methylation by the action of POL V, AGO4, methylases, and chromoproteins [21].

$(\mathrm{CaLCuV})$, the genomes which accumulate in the cell nucleus as minichromosomes, all of the four $A$. thaliana DCLs are involved in viral siRNA (vsiRNA) production [8, 30, 65]. In contrast, for RNA viruses, which are restricted to the cytoplasm, 21nt and 22nt siRNAs, produced by DCL4 and DCL2, are mainly involved [29, 65, 66]. The reason for this difference might be that DCL4 and DCL2 can also be available in the cytoplasm, while DCL3 and DCL1 are exclusively localized in the nucleus. Interestingly, viruses have developed countermeasures to meet the silencing strategy, namely, silencing suppressors, which interfere with dicing, RISC-formation, RDR activity, and others [8, 67, 68].

The dsRNA substrates used for siRNA production can be formed by annealing of sense and antisense transcripts, by intramolecular pairing leading to formation of hairpins or, in an increasing number of cases, by synthesis from single strand RNA (ssRNA) templates by RDRs. Several host RDRs produce dsRNAs from "aberrant" RNA templates [69].

The aberrant nature of these templates is ill defined, but they most likely correspond to uncapped RNAs and/or RNAs without or with only short polyA tails. These aberrant RNAs might arise from premature termination, regulated polyA tail shortening, decapping, or, as discussed in the following, the action of miRNA- or siRNA-guided cleavage of an RNA target.

Obviously, RNA viruses are replicated by viral RDRs (Figure 2), and despite immediate conversion of the nascent RNA copies into polysomes or virus particles, some might escape and form dsRNAs. Some viruses have dsRNAs as genomes, which are replicated within virus particles and thus are generally shielded from dicing; these particles may occasionally disrupt and release their genome. Geminiviral dsRNAs might arise from bidirectional read-through transcription of the circular DNA genome $[64,70]$. In the case of CaMV, a noncoding aberrant " $8 \mathrm{~S}$ " RNA is produced and replicated to dsRNA by the activity of an unknown protein which may correspond to POL II [71].

\section{A Role of Secondary siRNAs in the Spread of RNA Silencing}

Plants, nematodes, and fungi have the unique property to generate and amplify secondary (sec-) siRNAs. These secsiRNAs are responsible for the transitivity and spreading of RNA silencing. They can be induced artificially by VIGS vectors carrying host gene sequences or by transgenically expressed genes [14, 72-74].

Cell-specific inverted repeat transgenes have been used in A. thaliana to trigger the production of siRNAs, which were shown to cause primary posttranscriptional silencing and to spread over 10-15 cells (Figure 3) [75-78]. This short distance movement was shown to be RDR6 independent $[78,79]$. Thus, specifically in the case of transgenes, further RNA silencing movement was shown to depend on reiterated RDR-mediated amplification followed by short-distance cellto-cell movement [78]. In most plants, long-distance RNA silencing spread depends on movement through the phloem. However, long-range root-to-shoot silencing in Arabidopsis spreads largely by a series of cell-to-cell short-range mobile silencing events [80].

In the case of both, cell-to-cell movement and longdistance movement, the silencing signals include siRNAs [75, $76,80]$. However, whether this movement involves singlestranded siRNAs and/or siRNA duplexes and whether these are bound to dedicated cellular "movement proteins," like AGOs, remain to be clarified. These sec-siRNAs can be 21 t or 22nt long when generated by DCL4 and DCL2, respectively, and they can be involved in posttranscriptional gene silencing (PTGS), or 24nt long when generated by DCL3, and then be involved in transcriptional gene silencing (TGS). 


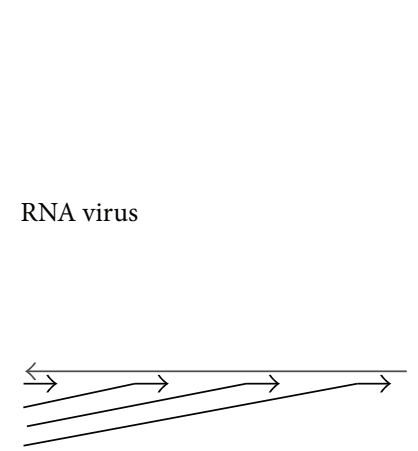

(a)

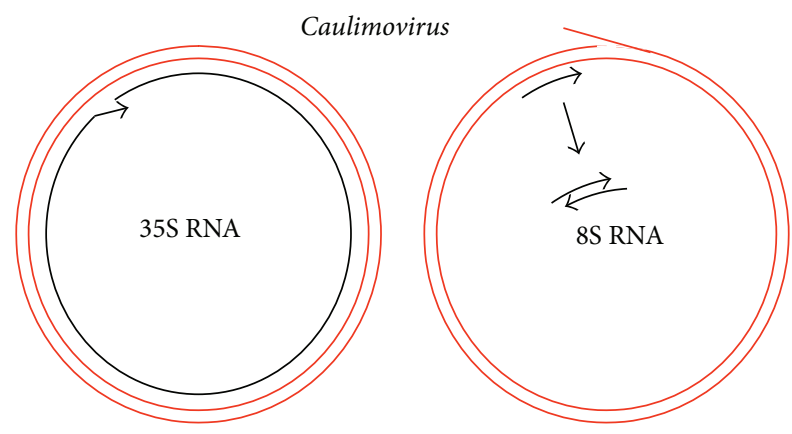

(c)

FIGURE 2: Viral dsRNA formation. (a) RNA-virus RNAs are replicated by viral RNA polymerases producing plus strands from a minus strand and vice versa. Occasionally, dsRNA is formed, namely, before the viral strands can be packaged or are protected by ribosomes. (b) Read-through transcription prior to polyadenylation leads to overlapping transcripts in geminiviruses. (c) Cauliflower mosaic virus and other caulimoviruses produce a specific dsRNA covering the leader region. This dsRNA and its siRNA products are thought to act as decoy, the latter by forming nonfunctional RISCs.

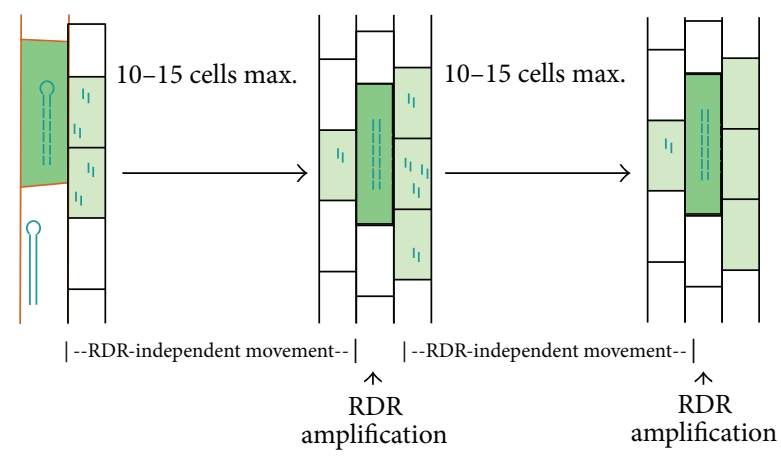

FIGURE 3: RDR-independent and RDR-dependent spreading of siRNAs. siRNAs can spread about 10 to 15 cell layers. Further spreading requires amplification.

\section{Complex Control Mechanisms Guided by sRNAs}

siRNA and miRNA transport serves in the plant for various types of complex control mechanisms [81]. Silencing enzymes can be absent or at least underrepresented in certain cells. Thus, the methylase DDM1 is not expressed in the vegetative nucleus of plant embryos. As a consequence, transposons are released, a part of which gives rise to transposon-specific $21 \mathrm{nt}$ long siRNAs. Those traffic to sperm cells and there reinforce the silencing of transposons, with the consequence that the embryos are protected from transposition (Figure 4(a)). This mechanism is further reinforced during seed development, where DNA in the endosperm is hypomethylated leading again to transposon release and accumulation of corresponding siRNAs. These move into the embryo to silence transposable elements (Figure 4(b)) [82].

Micro- and ta-si-RNAs can function as morphogens and determine patterning. For example, SHORT ROOT, a transcription factor produced in the vascular cylinder, moves into the endodermis, activates another transcription factor (SCARECROW) there, and together with it activates miR165 and miR166 transcription. These miRNAs move back to the vascular cylinder to encounter their target RNAs, which encode HD-ZIP transcription factors involved in xylem patterning (Figure 4(c)) $[63,99]$.

Arabidopsis leaf primordial TAS3a precursor RNA is another example. It is exclusively produced in the L1 and L2 adaxial (upper) leaf layers [81, 100-103]. TAS3 derived tasiRNAs target auxin response factors (ARFs) 3 and 4 [28, 84, 85, 104-106]. While ARF3 is detected throughout the whole leaf primordial, ARF 4 is exclusively expressed in abaxial (lower) leaf tissue. Since ARFs are targeted throughout the whole leaf primordia, TAS3-derived siRNAs must travel from the adaxial to the abaxial side of the leaf, forming a gradient (Figure $4(\mathrm{~d})$ ) and thereby contributing to the establishment of leaf tissue identity. Recent work by SiAmmour, Windels, and colleagues [92] highlighted a role for siRNAs derived from TIR/AFB2 auxin receptor (TAAR) transcripts in the regulation of auxin signaling homeostasis and of leaf morphogenesis $[91,92]$. However, the movement and the precise role in patterning of siTAARs has not yet been established [91, 92].

\section{A Role of Secondary siRNAs in Transitive RNA Silencing}

In some cases, the biogenesis of sec-siRNAs extends towards regions upstream and downstream of the initial target site, a phenomenon called "transitivity" [107-109]. Transitivity in RNA silencing depends on the type and location of the gene affected. For unclear reasons, transgenes are more prone to transitivity than endogenes [74, 108, 110, 111]. A possible explanation might be their high transcription rate that possibly generates more aberrant transcripts and thus more siRNAs than endogens do. Also, transitivity in $5^{\prime}-$ to $3^{\prime}$ direction is more often observed than in $3^{\prime}-$ to $5^{\prime}$-direction.

A reason for this differential susceptibility for transitivity might be that the fragments created by RISC-directed cleavage are not only substrates for RDRs but also for exonucleases (e.g., of the XRN family ${ }^{1}$ ) and exosomes (Figure $5(\mathrm{a})$ ). One can speculate that RDRs are more efficient or faster enzymes than exonucleases and that the high number of transcripts available for transgenes reaches easily the 


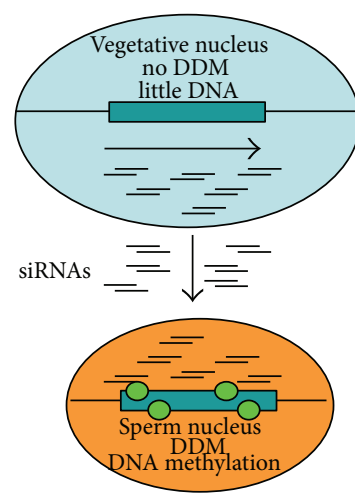

(a)

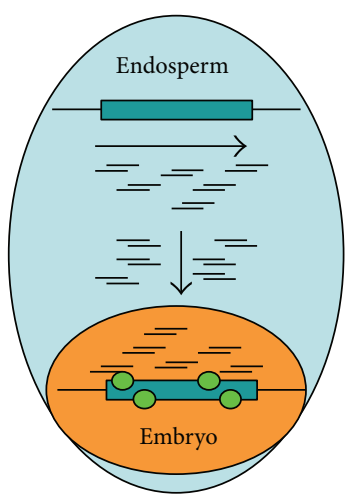

(b)

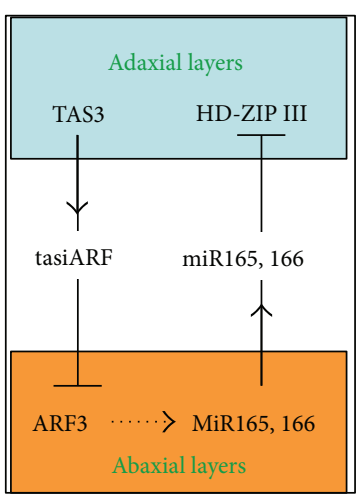

(c)

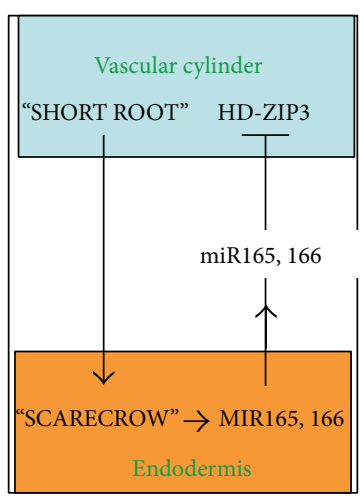

(d)

FIGURE 4: Gene regulation by sRNA movement. (a) Release of siRNAs from transposons in the vegetative nucleus. Those are transported to the sperm nucleus enforcing transposon silencing there. (b) A similar mechanism leads to siRNAs production in the endosperm and their role in embryo chromatin silencing. (c) Control of adaxial and abaxial identity through ta-siRNA and miRNA gradients. (d) Control of xylem patterning through miRNA gradients [63].

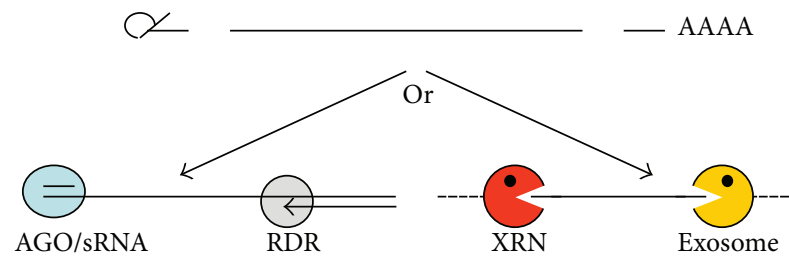

(a)

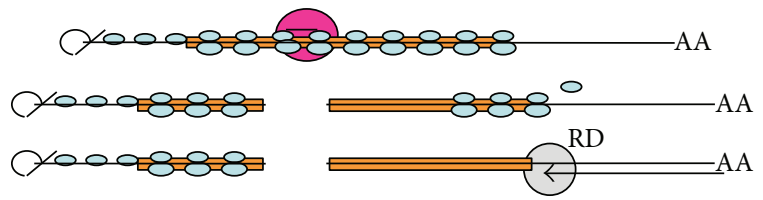

(b)

FIGURE 5: Differential susceptibility of RNAs for transitivity as such and for the direction of transitivity. (a) RDR and RNA-degrading enzymes compete for aberrant RNA. (b) Possible shielding of RNA from RDR activity by scanning and translating ribosomes.

threshold for triggering of RNA silencing. It is also possible that yet undefined properties of the RNA fragments attract preferentially either the degrading exonucleases or the RDR synthesizing enzymes. As an alternative, the composition of the RISC might determine the fate of the fragment. In fact, this is the case for the programmed production of ta-siRNAs and ra-siRNAs, described in the following.

A reason for the preferred $5^{\prime}-3^{\prime}$ direction of transitivity might be based on the nature of the RNA fragments created by the initial dicing. We speculate that if the target is within the $5^{\prime}$-UTR or the coding region of an RNA, then the diced 5 -fragment might be shielded from RDR activity by scanning and translating ribosomes, while the 3 -fragment is not. Consequently, only the RNA downstream of the primary dicing site leads to biogenesis of siRNAs (Figure 5(b)). Recent work infecting Arabidopsis carrying a GFP transgene with

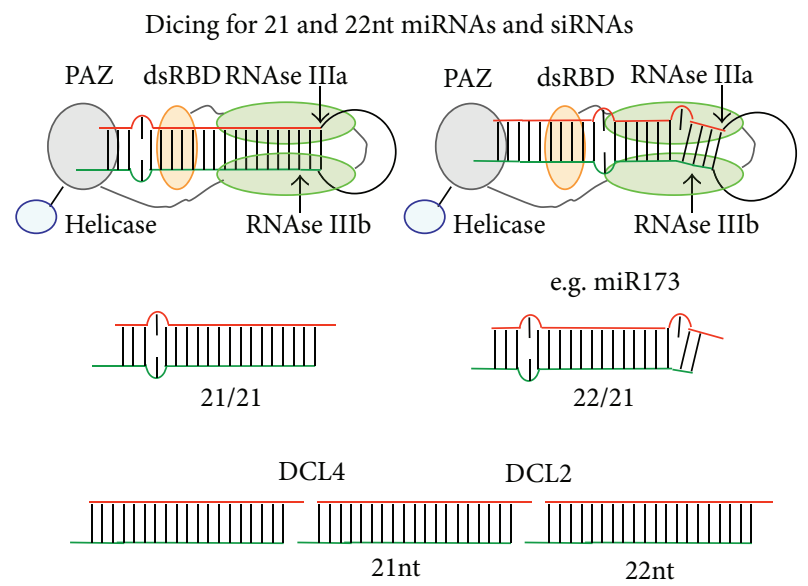

FIGURE 6: Production of 22nt sRNAs. 22nt miRNAs can be produced from asymmetrically bulged miR-precursors; 22nt siRNAs are produced from dsRNA by DCL2, while DCL4 produces $21 \mathrm{nt}$ ones.

geminivirus VIGS vectors loaded with a series of fragments of this GFP transgene supports this model [111].

\section{Programmed Triggering of Secondary siRNAs Formation}

Genome-wide studies have unravelled several cases of programmed transitivity for endogenes [89]. This programmed transitivity and the corresponding secondary siRNAs originate from various loci and from different types of noncoding (TAS) transcripts (ta-siRNAs) and coding transcripts (sitars, and pha-siRNAs) [24, 25, 85, 89, 91-95].

The common trigger for the biogenesis of sec-siRNAs, ta-siRNAs, and pha-siRNAs is a sRNA-guided slicing event $[89,92,94,112]$. In the case of certain trans-acting siRNAs and some other sec-siRNAs, two slicing events are necessary 
to trigger their formation from the central released fragment $[83,89]$. However this model did not explain the biogenesis of certain low abundant sec-siRNAs that were generated upon a unique slicing event. Bioinformatics analysis comparing sRNA (siRNA and miRNA) target pairs revealed that secondary siRNAs arise predominantly from RNAs that are initially targeted by sRNAs of 22nt in length $[113,114]$.

Thus, it is now clear that a single slicing event guided by a 22 nt sRNA rather than by another size-class sRNA is necessary and sufficient to initiate transitivity. In A. thaliana, the genetic observation that $d c l 2$ mutations eliminate hairpin transgene-induced accumulation of sec-siRNAs, while dcl4 mutations simply caused a shift in transitive silencing, was an important step towards implicating $22 \mathrm{nt}$ in triggering secsiRNA biogenesis [14].

22nt long miRNAs are produced from miRNA precursors with an asymmetric hairpin, that is, if bulged on the leading strand, or if a two-nucleotide bulge interrupts the double strand (Figure 6). Mutational analysis showed that removing the bulge in the precursor leads to production of a $21 \mathrm{nt}$ rather than a 22nt long miRNA and that although this $21 \mathrm{nt}$ miRNA is still active in slicing, it does not initiate transitivity. Likewise, artificial miRNA target pairs led to tasiRNA production if the miRNA partner was $22 \mathrm{nt}$ long and not if it was 21nt long [113-116].

Recent works showed that the presence of a $22 \mathrm{nt}$ complementary strand in siRNA duplexes is sufficient to initiate transitivity. Thus, these works showed that the programming of sec-siRNA biogenesis occurs at the level of RISC loading before the sRNA strands are separated. These works suggest that the 22nt sRNA duplexes induce a conformational change in AGO protein that allows them to recruit RDR6, SGS3, or another component of the transitivity machinery [117].

The original discovery of the trans-acting pathway highlighted that this class of secondary siRNAs appears to be generated in a phased fashion $[24,25]$. This feature, which was confirmed later by the analysis of large sRNA datasets and by molecular genetics experiments, is a hallmark of tasiRNAs which has been extensively used for the search of novel secondary siRNA loci $[85,90,106,118]$.

TAS RNAs are capped and polyadenylated and do not code for proteins. Upon slicing and in presence of the cofactor SGS3, TAS RNAs are converted to dsRNAs by RDR6. Upon dicing by DCL4, these dsRNAs spawn swarms of 21- and occasionally 22 nt long ta-siRNA duplexes $[24,83,89,112$, 119]. In A. thaliana, four groups of TAS RNAs were found, TAS1, TAS2, TAS3, and TAS4 (Table 1; Figure 7). ta-siRNA production from TAS1a,b,c and TAS2 RNAs is initiated by the 22nt long miR173::AGO1 RISC (e.g., Figures 7(a) and 7(b)) and from TAS4 by the 22nt long miR828::AGO1 RISC $[113,120]$. A notable exception concerns TAS3, from which ta-siRNA production is initiated by two $21 \mathrm{nt}$ long miR390::AGO7 RISCs, whereby only the second one leads to slicing, while the first one is simply anchored (Figure 7(b)) $[83,105]$.

As miRNAs initiate phased siRNA production from TASRNAs, the question is obvious, whether they could also do so from targeted mRNAs. Bioinformatic and molecular biology studies in various plant species showed that in fact they can

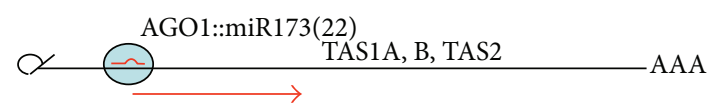

(a)

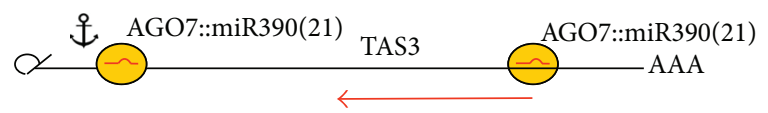

(b)

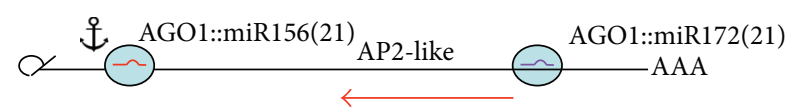

(c)

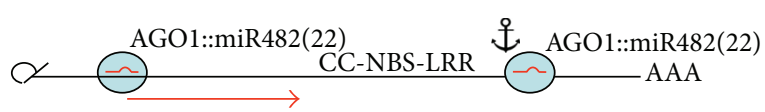

(d)

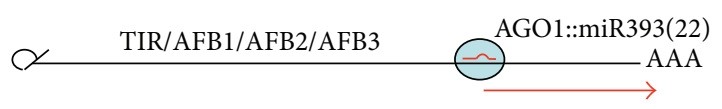

(e)

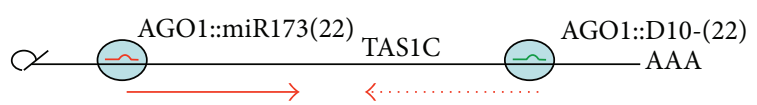

(f)

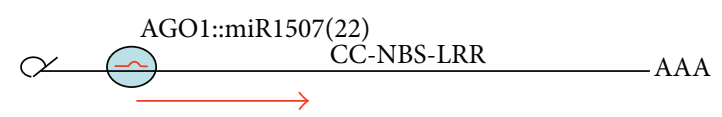

(g)

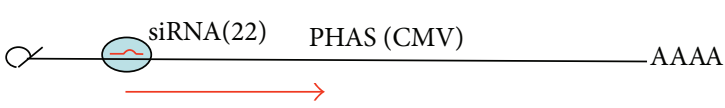

(h)

FIgURE 7: Examples of ta-siRNA and pha-siRNA production. Numbers in parentheses indicate the size of the sRNA considered. the red arrow intends to indicate the direction of transitivity. For details, see the text.

(Table 1). Many of these cases concern mRNAs encoding pentatricopeptide proteins (PPRs) ${ }^{2}$.

Recent works by Windels and Vazquez have shown that the regulation of auxin signaling homeostasis depends on a network of sec-siRNAs, termed siTAARs (Figure 8) [91]. Like other sec-siRNAs, siTAARs are generated upon miRNAguided slicing. In this case, miR393b was shown to guide the cleavage of all four transcripts of the TIR/AFB2 auxin receptor (TAAR) clade and to trigger the biogenesis of secsiRNAs for at least two of these members. siTAARs were shown to act in cis on their own source transcripts as well as in trans on homologous TAAR transcripts and on unrelated transcripts [92]. siTAARs were shown to be important for some aspect of leaf development, but their precise role in supplementing the function of miR393 remains to be clarified. Analysis of miR393 size in different plant lineages shows that the 22nt size is conserved in at least 7 species out of 22 in which miR393 was sequenced (8) [91]. Thus, if we assume that the biogenesis of siTAARs depends on a $22 \mathrm{nt}$ 
TABLE 1: MicroRNAs and ta-siRNAs targeting RNAs for secondary siRNA production.

\begin{tabular}{|c|c|c|c|c|c|c|c|c|}
\hline & $\mathrm{nt}$ & $5^{\prime}$ & AGO & Hits & Sec-siRNA source & RNA Targets & Model & References \\
\hline $\operatorname{miR} 173$ & 22 & $\mathrm{U}$ & 1 & 1 & TAS1a,b,c,2 & Pentatricopeptide repeat proteins & A.t. & {$[24,25,83]$} \\
\hline $\operatorname{miR} 390$ & 21 & & 7 & 2 & TAS3 & Auxin response factors & Plants & {$[84-86]$} \\
\hline $\operatorname{miR} 828$ & 22 & $\mathrm{U}$ & 1 & 1 & TAS4 & MYB transcription factors & & {$[87,88]$} \\
\hline $\mathrm{miR} 161 / \mathrm{miR} 400$ & 21 & & 1 & 2 & PPR clade & PPR network & A.t. & {$[89,90]$} \\
\hline $\operatorname{miR} 393$ & 22 & & 1 & 1 & siTAAR & TAAR network & & {$[89,91,92]$} \\
\hline $\operatorname{miR} 472$ & 22 & & 1 & 1 & NBS-LRR & NBS-LRR & A.t. & {$[89]$} \\
\hline $\operatorname{miR} 482$ & 22 & & 1 & 2 & NBS-LRR & NBS-LRR & Tomato & {$[93]$} \\
\hline miR780/miR856 & 21 & & & & ATCHX18 & & & [89] \\
\hline $\operatorname{miR} 2118$ & 22 & $\mathrm{U}$ & 1 & 1 & NBS-LRR; SGS3 & & Plants & {$[93,94]$} \\
\hline $\operatorname{miR} 6019$ & 22 & & & & NBS-LRR (N) & & Tobacco & {$[95]$} \\
\hline $\operatorname{miR} 6020$ & 21 & & & & NBS-LRR (N) & & Tobacco & {$[95]$} \\
\hline $\operatorname{miR} 2109$ & 22 & $\mathrm{U}$ & 1 & 1 & NBS-LRR & & Medicago & {$[94]$} \\
\hline $\operatorname{miR} 1507$ & 22 & $\mathrm{C}$ & 1 & 1 & NBS-LRR; DCL2 & & Medicago & {$[94]$} \\
\hline $\operatorname{miR} 1509$ & 22 & & 1 & 2 & & & Medicago & {$[94]$} \\
\hline $\operatorname{miR} 5754$ & 22 & $\mathrm{U}$ & 1 & 1 & & & Medicago & {$[94]$} \\
\hline miR156/miR172 & $21 / 21$ & $\mathrm{U} / \mathrm{A}$ & $1 / 1$ & 2 & AP2-like & & Medicago & {$[94]$} \\
\hline tas1c D6- & 21,22 & $\mathrm{U}$ & $1,2,4$ & & TAS 1a,b,c, TAS2 & & A.t. & [96] \\
\hline tas1c D10- & 21 & A & 2 & & TAS1c & & A.t. & {$[96]$} \\
\hline tas1c D10- & 22 & $\mathrm{U}$ & 1 & & TAS1c & & A.t. & {$[96]$} \\
\hline tas3 D2- & 21 & & & & TAS3 & & Leguminosae & {$[97]$} \\
\hline $\operatorname{miR} 168$ & 22 & & & 1 & AGO1 & & A.t., Tomato & {$[93,98]$} \\
\hline
\end{tabular}

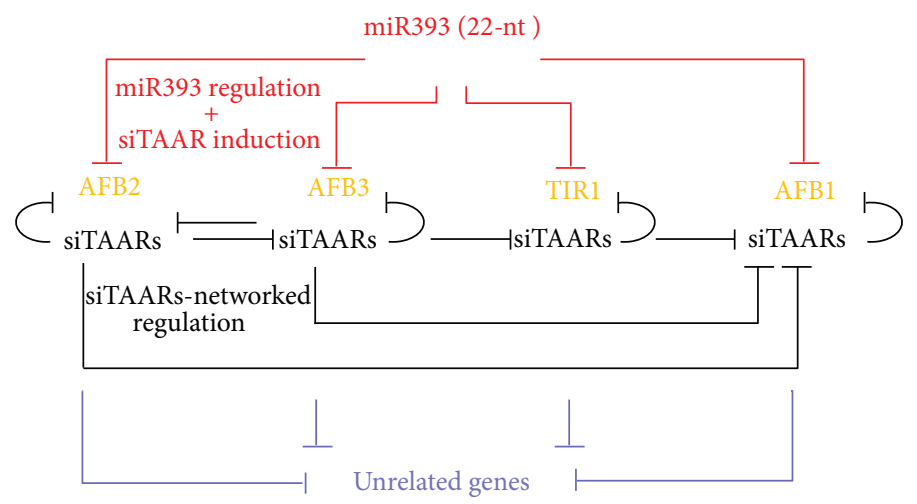

FIGURE 8: Complex network regulation of siTAARs initiated by miR393. Upon cleavage of TIR1/AFB2 auxin receptor (TAAR) transcripts by miR393 (red lines), secondary siRNAs (siTAARs) are generated. siTAARs regulate the expression of their source transcript in cis (dark lines) of other TAAR transcripts in trans (transverse dark lines) and of unrelated transcripts (blue lines) in trans. The network has important role in auxin homeostasis and plant development.

miR393 in other plant species as well, we speculate that the developmental functions of siTAARs might be conserved.

Other recent works showed that also miRNAs that target pathogen resistance R-genes, especially of the nucleotidebinding leucine-rich repeat (NBS-LRR) ${ }^{3}$ type, are controlled by secondary siRNAs that were termed pha-siRNAs. Those were described mainly for Solanaceae $[93,95]$ and Leguminosae [94].

Like TAS RNAs, the corresponding PHAS RNAs are either targeted by double hits, with only one of them leading to slicing while the other is anchored (Table 1; Figures 7(a), $7(\mathrm{~b})$, and $7(\mathrm{~d})$ ) or a single hit (Figure $7(\mathrm{~h})$ ). In the latter case, usually 22nt miRNAs are involved. In few cases of double hits, two different miRNAs or siRNAs interact with the $5^{\prime}-$ and $3{ }^{\prime}-$ site [89]. Dicing can occur from the right (Figures 7 (b) and 7(c)), the left, or from both sides (Figure 7(f)).

Recent bioinformatics works have suggested that at least 4 novel TAS families exist in grapevine although they need to be experimentally validated and their biological role remains to be clarified [118]. 


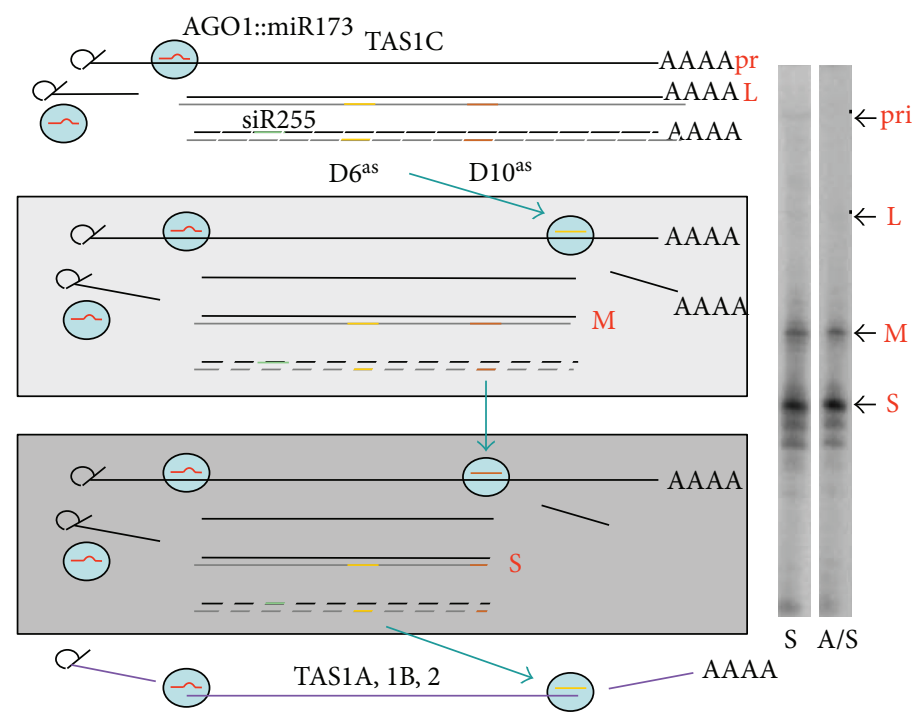

FIgURE 9: Cascades involving TAS1 and TAS2 processing in Arabidopsis. The results rely on the use of CaMV infected plants of which the suppressor TAV interferes with the DCL4/DRB4 activity. The dsRNA intermediates generated by RDR6 accumulating in CaMV infected plants were analyzed. For TAS1c, three main dsRNAs accumulated. The largest and minor one corresponds to a single cut of TAS1c RNA by the AGO1::mir173 RISC, the second one from a double hit by AGO1::miR173 and AGO1::D6 ${ }^{\text {as }}$, and the third one by AGO1::miR173 and AGO1(2)::D10 ${ }^{\text {as }} . \mathrm{D}^{\text {as }}$ and $\mathrm{D} 10^{\text {as }}$ are siRNAs at positions 6 and 10 derived from the antisense strand of the dsRNA intermediate. D10 ${ }^{\text {as }}$ exists as a $21 \mathrm{nt} 5^{\prime} \mathrm{A}$ form likely bound to AGO2 and a $22 \mathrm{nt} 5^{\prime} \mathrm{U}$ form bound to AGO1. Notably, D6 ${ }^{\text {as }}$ RISCs can also target TAS1a, TAS1b, and TAS2 RNAs. On the right, a gel ss showed separating single and double-stranded ta-siRNA precursors (S sense RNAs, AS, antisense RNAs).

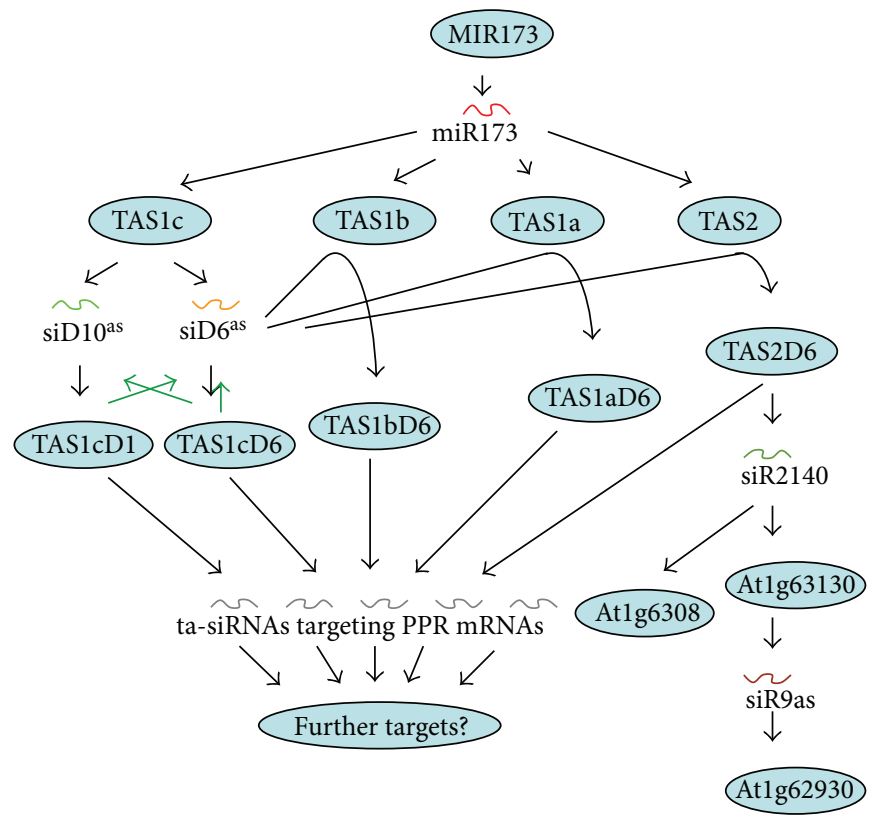

FIGURE 10: Cascades initiated by miR173 interaction with TAS1 RNAs. Cartouches show precursor RNAs, which give rise to ta-siRNAs and pha-siRNAs that attack further precursor RNAs leading to cascades of gene regulation.

\section{Cascades $^{3}$}

We discussed previously that the targeting of RNAs by miRNAs and siRNAs can lead to the production of ta-siRNAs, siTAARs, and pha-siRNAs. These secondary sRNAs could initiate further layers of sRNA production and form extensive cascades and networks of gene regulation. Bioinformatics and molecular evidence for this was reported in $[90,113,121]$.

Recent works by Rajeswaran et al. [96] have shown that an internal cascade exists for the biogenesis of TAS1 and TAS2 siRNAs in Arabidopsis [96]. The work, which takes advantage of the inhibition of DCL4/DRB4 processing step 
by the CaMV silencing suppressor TAV, allowed to identify the supposed TAS dsRNA intermediates and suggested that the 22nt long siRNA D6(-) produced from TAS1c generates the second hits in TAS1a, TAS1b, and TAS2 RNAs (Figure 9).

The cascade is known to further continue at least from TAS2 and TAS2D6, giving rise to siR2140 [90], which targets at least two PPR mRNAs. One of these targeted RNAs gives again rise to dsRNA spawning siRNAs, one of which targets a third PPR mRNA (Figure 10). Thus, a cascade originating from miR173 has altogether at least four steps.

The frequent cases of pha-siRNA production from NB$\mathrm{LRR}^{4}$ mRNAs of various plant families [93-95] make it likely that at least some of them target other genes. Since there are many NB-LRR-genes present in plants and those related, phasiRNAs derived from one NB-LRR mRNA could well target a related one. But pha-siRNAs might also target other mRNAs. Shivaprasad et al., for instance, identified a PEN3 like mRNA involved in basal immunity and a proteosome subunit one as secondary targets of tomato miR482 [93].

\section{Acknowledgments}

F. Vazquez and T. Hohn would like to thank Thomas Boller and Christian Körner for hosting the groups at the Botanical Institute and MM Pooggin for long-standing collaboration. The work in the F. Vazquez lab is supported by Grants from the Swiss National Science Foundation (PZ00P3_126329 and PZ00P3_142106) and in the T. Hohn lab by Grants from Swiss National Science Foundation (31003A_132332), Indo-Swiss Collaboration in Biotechnology, and COST Action FA0806.

\section{Endnotes}

1. Decapped and deadenylated RNAs are supposedly degraded by XRNs in $5^{\prime}-$ to $3^{\prime}$-direction and by the exosomes in $3^{\prime}$ - to $5^{\prime}$-direction [109]. Competition between RNA degradation by XRN4 and RDR activity $[122,123]$ has been observed for several transgenes. However, whether this antagonistic relationship occurs for endogenes is unclear. Indeed, TAS transcripts of the TAS1 and TAS2 families were shown to escape such antagonistic feature [27, 124]. Gregory et al. [124] observed that $x r n 4$ mutants accumulate low-abundant sRNAs from hundreds of protein-coding loci which were normally not a source for sRNA [124]. These observations showed that XRN4 functions as an antagonist of siRNA formation from certain endogenous transcripts. However, the features determining the different sources of sec-siRNAs remain to be clarified.

2. PPRs are modular superhelical proteins with each of the 35 "pentatrico"-aa-repeats binding to RNA motifs. The genes exist in plant genomes in the hundreds and are responsible for correct chloroplast and mitochondrial gene expression, that is, splicing, processing, editing, translation initiation, and so forth [125].

3. Cascades are also used as means for strict control in other instances. Biological control frequently does not occur in single simple steps but in multiple steps including a cascade of events. This multiplicity allows for precise quantitative control. The single steps can lead either to positive or negative control (activation, repression) [126, 127]. Cascades have been described in mammalian immunology where antibodies are controlled by anti-antibodies and those again by anti-antiantibodies, and so forth [128], as MAP kinase cascades controlling pathogen response [129] or as transcription factor cascades [130].

4. NB-LRR genes: plants have two main types of defence (R) genes against bacteria, fungi, viruses, and other pathogens: leucine-rich repeat-receptor like kinases (LRR-RLK) and nucleotide-binding leucine-rich repeat (NB-LRR) genes. The former ones are transmembrane proteins recognizing pathogen-associated molecular patterns (PAMPs) outside the cell and involved in the first line of defence alerting the organism. The second class recognizes pathogen effectors inside the cell and induces hypersensitive reactions (HRs) leading to cell death and to systemic acquired resistance (SAR). NBS-LRR genes are abundant and highly variable in all plants analyzed so far [131]. NB-LRR genes seem to evolve fast adapting to the appearance of new variants of pathogens. Due to the high costs of the defence, NB-LRR genes are highly controlled, and recent research revealed a major role in posttranscriptional silencing involving miRNAs and secondary pha-siRNA cascades in this task $[94,95]$. Shivaprasad et al. [93] observed that in fact the targeting of NB-LRR RNAs is strongly reduced upon infection by bacteria or viruses. Apparently, effectors and/or silencing suppressors are responsible for this. As a consequence, the plant is alert for a possible pathogen attack due to the presence of NB-LRR-mRNAs but is inhibiting their expression until the pathogen response is really needed [93]. Likewise, mRNAs coding for components of the silencing system are targeted by silencing, for example, SGS3 by miR2118, DCL2 by miR1507, and AGO1 by miR168 (Table 1), and this silencing could be relieved upon virus-directed silencing suppression. Moreover, also the mammalian innate immune system is controlled by anti-inflammation devices [132] and the acquired immune system by networks of anti-antibodies [128].

\section{References}

[1] M. Zaratiegui, D. V. Irvine, and R. A. Martienssen, "Noncoding RNAs and gene silencing," Cell, vol. 128, no. 4, pp. 763-776, 2007.

[2] J. R. Haag and C. S. Pikaard, "Multisubunit RNA polymerases IV and V: purveyors of non-coding RNA for plant gene silencing," Nature Reviews Molecular Cell Biology, vol. 12, no. 8, pp. 483-492, 2011.

[3] M. S. Ebert and P. A. Sharp, "Roles for microRNAs in conferring robustness to biological processes," Cell, vol. 149, no. 3, pp. 515-524, 2012. 
[4] K. Kruszka, M. Pieczynski, D. Windels et al., "Role of microRNAs and other small RNAs of plants in their changing enviroments," Journal of Plant Physiology, vol. 169, pp. 1664-1672, 2012.

[5] C. Llave, "Virus-derived small interfering RNAs at the core of plant-virus interactions," Trends in Plant Science, vol. 15, no. 12, pp. 701-707, 2010.

[6] T. Csorba, V. Pantaleo, and J. Burgyán, "RNA silencing: an antiviral mechanism," Advances in Virus Research, vol. 75, pp. 35-71, 2009.

[7] S. W. Ding, "RNA-based antiviral immunity," Nature Reviews Immunology, vol. 10, no. 9, pp. 632-644, 2010.

[8] T. Hohn and F. Vazquez, "RNA silencing pathways of plants: silencing and its suppression by plant DNA viruses," Biochimica et Biophysica Acta, vol. 1809, no. 11-12, pp. 588-600, 2011.

[9] V. R. Sanghvi and L. F. Steel, "RNA silencing as a cellular defense against HIV-1 infection: progress and issues," FASEB Journal, vol. 26, no. 10, pp. 3937-3945, 2012.

[10] C. G. Duan, C. H. Wang, and H. S. Guo, "Application of RNA silencing to plant disease resistance," Silence, vol. 3, no. 1, p. 5, 2012.

[11] G. Gómez, G. Martínez, and V. Pallás, "Viroid-induced symptoms in Nicotiana benthamiana plants are dependent on RDR6 activity," Plant Physiology, vol. 148, no. 1, pp. 414-423, 2008.

[12] B. Navarro, A. Giselb, M. E. Rodio et al., "Viroids: how to infect a host and cause disease without encoding proteins," Biochimie, vol. 94, no. 7, pp. 1474-1480, 2012.

[13] R. A. Mosher and C. W. Melnyk, "siRNAs and DNA methylation: seedy epigenetics," Trends in Plant Science, vol. 15, no. 4, pp. 204-210, 2010.

[14] S. Mlotshwa, G. J. Pruss, A. Peragine et al., "Dicer-like2 plays a primary role in transitive silencing of transgenes in Arabidopsis," PLoS ONE, vol. 3, no. 3, article e1755, 2008.

[15] S. Katiyar-Agarwal and H. Jin, "Role of small RNAs in hostmicrobe interactions," Annual Review of Phytopathology, vol. 48, pp. 225-246, 2010.

[16] O. Voinnet, "Micro-balancing innate immunity to Salmonella," EMBO Journal, vol. 30, no. 10, pp. 1877-1879, 2011.

[17] F. Vazquez, S. Legrand, and D. Windels, "The biosynthetic pathways and biological scopes of plant small RNAs," Trends in Plant Science, vol. 15, no. 6, pp. 337-345, 2010.

[18] A. Mallory and H. Vaucheret, "Form, function, and regulation of ARGONAUTE proteins," Plant Cell, vol. 22, no. 12, pp. 3879-3889, 2010.

[19] O. Voinnet, "Origin, biogenesis, and activity of plant MicroRNAs," Cell, vol. 136, no. 4, pp. 669-687, 2009.

[20] E. J. Chapman and J. C. Carrington, "Specialization and evolution of endogenous small RNA pathways," Nature Reviews Genetics, vol. 8, no. 11, pp. 884-896, 2007.

[21] M. Matzke, T. Kanno, L. Daxinger, B. Huettel, and A. J. Matzke, "RNA-mediated chromatin-based silencing in plants," Current Opinion in Cell Biology, vol. 21, no. 3, pp. 367-376, 2009.

[22] C. S. Pikaard, J. R. Haag, T. Ream, and A. T. Wierzbicki, "Roles of RNA polymerase IV in gene silencing," Trends in Plant Science, vol. 13, no. 7, pp. 390-397, 2008.

[23] A. Verdel, A. Vavasseur, M. Le Gorrec, and L. Touat-Todeschini, "Common themes in siRNA-mediated epigenetic silencing pathways," International Journal of Developmental Biology, vol. 53, no. 2-3, pp. 245-257, 2009.
[24] F. Vazquez, H. Vaucheret, R. Rajagopalan et al., "Endogenous trans-acting siRNAs regulate the accumulation of arabidopsis mRNAs," Molecular Cell, vol. 16, no. 1, pp. 69-79, 2004.

[25] A. Peragine, M. Yoshikawa, G. Wu, H. L. Albrecht, and R. S. Poethig, "SGS3 and SGS2/SDE1/RDR6 are required for juvenile development and the production of trans-acting siRNAs in Arabidopsis," Genes and Development, vol. 18, no. 19, pp. 2368-2379, 2004.

[26] Y. Nakazawa, A. Hiraguri, H. Moriyama, and T. Fukuhara, "The dsRNA-binding protein DRB4 interacts with the Dicerlike protein DCL4 in vivo and functions in the trans-acting siRNA pathway," Plant Molecular Biology, vol. 63, no. 6, pp. 777-785, 2007.

[27] M. Yoshikawa, A. Peragine, Y. P. Mee, and R. S. Poethig, "A pathway for the biogenesis of trans-acting siRNAs in Arabidopsis," Genes and Development, vol. 19, no. 18, pp. 2164-2175, 2005.

[28] X. Adenot, T. Elmayan, D. Lauressergues et al., "DRB4dependent TAS3 trans-acting siRNAs control leaf morphology through AGO7," Current Biology, vol. 16, no. 9, pp. 927-932, 2006.

[29] A. Deleris, J. Gallago-Bartolome, J. Bao, K. D. Kasschau, J. C. Carrington, and O. Voinnet, "Hierarchical action and inhibition of plant dicer-like proteins in antiviral defense," Science, vol. 313, no. 5783, pp. 68-71, 2006.

[30] T. Blevins, R. Rajeswaran, P. V. Shivaprasad et al., "Four plant Dicers mediate viral small RNA biogenesis and DNA virus induced silencing," Nucleic Acids Research, vol. 34, no. 21, pp. 6233-6246, 2006.

[31] F. Vazquez, T. Blevins, J. Ailhas, T. Boller, and F. Meins, "Evolution of Arabidopsis MIR genes generates novel microRNA classes," Nucleic Acids Research, vol. 36, no. 20, pp. 6429-6438, 2008.

[32] I. R. Henderson, X. Zhang, C. Lu et al., "Dissecting Arabidopsis thaliana DICER function in small RNA processing, gene silencing and DNA methylation patterning," Nature Genetics, vol. 38, no. 6, pp. 721-725, 2006.

[33] X. Zhanga, X. Zhanga, J. Singha, D. Lic, and F. Qua, "Temperature-dependent survival of Turnip crinkle virusinfected arabidopsis plants relies on an RNA silencing-based defense that requires DCL2, AGO2, and HEN1," Journal of Virology, vol. 86, no. 12, pp. 6847-6854, 2012.

[34] S. Boutet, F. Vazquez, J. Liu et al., "Arabidopsis HEN1: a genetic link between endogenous miRNA controlling development and siRNA controlling transgene silencing and virus resistance," Current Biology, vol. 13, no. 10, pp. 843-848, 2003.

[35] W. Park, J. Li, R. Song, J. Messing, and X. Chen, "CARPEL FACTORY, a Dicer homolog, and HEN1, a novel protein, act in microRNA metabolism in Arabidopsis thaliana," Current Biology, vol. 12, no. 17, pp. 1484-1495, 2002.

[36] I. Papp, M. F. Mette, W. Aufsatz et al., "Evidence for nuclear processing of plant micro RNA and short interfering RNA precursors," Plant Physiology, vol. 132, no. 3, pp. 1382-1390, 2003.

[37] P. Chellappan, J. Xia, X. Zhou et al., "siRNAs from miRNA sites mediate DNA methylation of target genes," Nucleic Acids Research, vol. 38, no. 20, pp. 6883-6894, 2010.

[38] P. Brodersen, L. Sakvarelidze-Achard, M. Bruun-Rasmussen et al., "Widespread translational inhibition by plant miRNAs and siRNAs," Science, vol. 320, no. 5880, pp. 1185-1190, 2008. 
[39] E. Lanet, E. Delannoy, R. Sormani et al., "Biochemical evidence for translational repression by arabidopsis MicroRNAsW," Plant Cell, vol. 21, no. 6, pp. 1762-1768, 2009.

[40] C. Llave, Z. Xie, K. D. Kasschau, and J. C. Carrington, "Cleavage of Scarecrow-like mRNA targets directed by a class of Arabidopsis miRNA," Science, vol. 297, no. 5589, pp. 2053-2056, 2002.

[41] X. Chen, "A MicroRNA as a translational repressor of APETALA2 in arabidopsis flower development," Science, vol. 303, no. 5666, pp. 2022-2025, 2004.

[42] M. J. Aukerman and H. Sakai, "Regulation of flowering time and floral organ identity by a MicroRNA and its APETALA2-like target genes," Plant Cell, vol. 15, no. 11, pp. 2730-2741, 2003.

[43] F. Vazquez, "Arabidopsis endogenous small RNAs: highways and byways," Trends in Plant Science, vol. 11, no. 9, pp. 460-468, 2006.

[44] P. Brodersen and O. Voinnet, "The diversity of RNA silencing pathways in plants," Trends in Genetics, vol. 22, no. 5, pp. 268-280, 2006.

[45] X. Chen, J. Liu, Y. Cheng, and D. Jia, "HEN1 functions pleiotropically in Arabidopsis development and acts in C function in the flower," Development, vol. 129, no. 5, pp. 1085-1094, 2002.

[46] B. Szarzynska, L. Sobkowiak, B. D. Pant et al., "Gene structures and processing of Arabidopsis thaliana HYL1-dependent primiRNAs," Nucleic Acids Research, vol. 37, no. 9, pp. 3083-3093, 2009.

[47] M. H. Han, S. Goud, L. Song, and N. Fedoroff, "The Arabidopsis double-stranded RNA-binding protein HYL1 plays a role in microRNA-mediated gene regulation," Proceedings of the National Academy of Sciences of the United States of America, vol. 101, no. 4, pp. 1093-1098, 2004.

[48] F. Vazquez, V. Gasciolli, P. Crété, and H. Vaucheret, "The nuclear dsRNA binding protein HYL1 is required for microRNA accumulation and plant development, but not posttranscriptional transgene silencing," Current Biology, vol. 14, no. 4, pp. 346-351, 2004.

[49] L. Yang, Z. Liu, F. Lu, A. Dong, and H. Huang, "SERRATE is a novel nuclear regulator in primary microRNA processing in Arabidopsis," Plant Journal, vol. 47, no. 6, pp. 841-850, 2006.

[50] D. Lobbes, G. Rallapalli, D. D. Schmidt, C. Martin, and J. Clarke, "SERRATE: a new player on the plant microRNA scene," EMBO Reports, vol. 7, no. 10, pp. 1052-1058, 2006.

[51] B. Yu, L. Bi, B. Zheng et al., "The FHA domain proteins DAWDLE in Arabidopsis and SNIP1 in humans act in small RNA biogenesis," Proceedings of the National Academy of Sciences of the United States of America, vol. 105, no. 29, pp. 10073-10078, 2008.

[52] Z. Yang, Y. W. Ebright, B. Yu, and X. Chen, "HEN1 recognizes 21-24 nt small RNA duplexes and deposits a methyl group onto the 2 ' $\mathrm{OH}$ of the 3 'terminal nucleotide," Nucleic Acids Research, vol. 34, no. 2, pp. 667-675, 2006.

[53] B. Yu, Z. Yang, J. Li et al., "Methylation as a crucial step in plant microRNA biogenesis," Science, vol. 307, no. 5711, pp. 932-935, 2005.

[54] J. Li, Z. Yang, B. Yu, J. Liu, and X. Chen, "Methylation protects miRNAs and siRNAs from a $3^{\prime}$-end uridylation activity in Arabidopsis," Current Biology, vol. 15, no. 16, pp. 1501-1507, 2005.

[55] V. Ramachandran and X. Chen, "Degradation of microRNAs by a family of exoribonucleases in Arabidopsis," Science, vol. 321, no. 5895, pp. 1490-1492, 2008.
[56] Y. Zhao, Y. Yu, J. Zhai et al., “The Arabidopsis nucleotidyl transferase HESO1 uridylates unmethylated small RNAs to trigger their degradation," Current Biology, vol. 22, no. 8, pp. 689-694, 2012.

[57] G. Ren, X. Chen, and B. Yu, "Uridylation of miRNAs by hen 1 suppressor1 in Arabidopsis," Current Biology, vol. 22, no. 8, pp. 695-700, 2012.

[58] H. Vaucheret, F. Vazquez, P. Crété, and D. P. Bartel, “The action of ARGONAUTE1 in the miRNA pathway and its regulation by the miRNA pathway are crucial for plant development," Genes and Development, vol. 18, no. 10, pp. 1187-1197, 2004.

[59] N. Baumberger and D. C. Baulcombe, "Arabidopsis ARGONAUTE1 is an RNA Slicer that selectively recruits microRNAs and short interfering RNAs," Proceedings of the National Academy of Sciences of the United States of America, vol. 102, no. 33, pp. 11928-11933, 2005.

[60] K. W. Earley and R. S. Poethig, "Binding of the cyclophilin 40 ortholog SQUINT to Hsp90 protein is required for SQUINT function in Arabidopsis," The Journal of Biological Chemistry, vol. 286, no. 44, pp. 38184-38189, 2011.

[61] M. R. Smith, M. R. Willmann, G. Wu et al., "Cyclophilin 40 is required for microRNA activity in Arabidopsis," Proceedings of the National Academy of Sciences of the United States of America, vol. 106, no. 13, pp. 5424-5429, 2009.

[62] X. Chen, "Small RNAs and their roles in plant development," Annual Review of Cell and Developmental Biology, vol. 25, pp. 21-44, 2009.

[63] S. Miyashima, S. Koi, T. Hashimoto, and K. Nakajima, "Noncell-autonomous microRNA 165 acts in a dose-dependent manner to regulate multiple differentiation status in the Arabidopsis root," Development, vol. 138, no. 11, pp. 2303-2313, 2011.

[64] R. Rajeswaran and M. M. Pooggin, "Role of virus-derived small RNAs in plant antiviral defense: insights from DNA viruses," in MicroRNAs in Plant Development and Stress Responses, R. Sunkar, Ed., vol. 15 of Signaling and Communication in Plants, Springer, Berlin, Germany, 2012.

[65] R. Akbergenov, A. Si-Ammour, T. Blevins et al., "Molecular characterization of geminivirus-derived small RNAs in different plant species," Nucleic Acids Research, vol. 34, no. 2, pp. 462-471, 2006.

[66] Q. Hu, J. Hollunder, A. Niehl et al., "Specific impact of tobamovirus infection on the arabidopsis small RNA profile," PLoS ONE, vol. 6, no. 5, Article ID e19549, 2011.

[67] S. W. Ding and O. Voinnet, "Antiviral immunity directed by small RNAs," Cell, vol. 130, no. 3, pp. 413-426, 2007.

[68] R. T. Omarov and H. B. Scholthof, "Biological chemistry of virus-encoded suppressors of RNA silencing: an overview," Methods in Molecular Biology, vol. 894, pp. 39-56, 2012.

[69] F. Qu, "Antiviral role of plant-encoded RNA-Dependent RNA polymerases revisited with deep sequencing of small interfering RNAs of virus origin," Molecular Plant-Microbe Interactions, vol. 23, no. 10, pp. 1248-1252, 2010.

[70] P. V. Shivaprasad, R. Akbergenov, D. Trinks et al., "Promoters, transcripts, and regulatory proteins of Mungbean yellow mosaic geminivirus," Journal of Virology, vol. 79, no. 13, pp. 8149-8163, 2005.

[71] T. Blevins, R. Rajeswaran, M. Aregger et al., "Massive production of small RNAs from a non-coding region of Cauliflower mosaic virus in plant defense and viral counter-defense," Nucleic Acids Research, vol. 39, no. 12, pp. 5003-5014, 2011. 
[72] G. Moissiard, E. A. Parizotto, C. Himber, and O. Voinnet, "Transitivity in Arabidopsis can be primed, requires the redundant action of the antiviral Dicer-like 4 and Dicer-like 2, and is compromised by viral-encoded suppressor proteins," RNA, vol. 13, no. 8, pp. 1268-1278, 2007.

[73] A. Bleys, H. Van Houdt, and A. Depicker, "Down-regulation of endogenes mediated by a transitive silencing signal," RNA, vol. 12, no. 9, pp. 1633-1639, 2006.

[74] B. O. Petersen and M. Albrechtsen, "Evidence implying only unprimed RdRP activity during transitive gene silencing in plants," Plant Molecular Biology, vol. 58, no. 4, pp. 575-583, 2005.

[75] P. Dunoyer, G. Schott, C. Himber et al., "Small RNA duplexes function as mobile silencing signals between plant cells," Science, vol. 328, no. 5983, pp. 912-916, 2010.

[76] A. Molnar, C. W. Melnyk, A. Bassett, T. J. Hardcastle, R. Dunn, and D. C. Baulcombe, "Small silencing RNAs in plants are mobile and direct epigenetic modification in recipient cells," Science, vol. 328, no. 5980, pp. 872-875, 2010.

[77] P. Dunoyer, C. Himber, and O. Voinnet, "DICER-LIKE 4 is required for RNA interference and produces the 21-nucleotide small interfering RNA component of the plant cell-to-cell silencing signal," Nature Genetics, vol. 37, no. 12, pp. 1356-1360, 2005.

[78] C. Himber, P. Dunoyer, G. Moissiard, C. Ritzenthaler, and O. Voinnet, "Transitivity-dependent and -independent cell-to-cell movement of RNA silencing," EMBO Journal, vol. 22, no. 17, pp. 4523-4533, 2003.

[79] P. Dunoyer, C. Himber, V. Ruiz-Ferrer, A. Alioua, and O. Voinnet, "Intra- and intercellular RNA interference in Arabidopsis thaliana requires components of the microRNA and heterochromatic silencing pathways," Nature Genetics, vol. 39, no. 7, pp. 848-856, 2007.

[80] D. Liang, R. G. White, and P. M. Waterhouse, "Gene silencing in arabidopsis spreads from the root to the shoot, through a gating barrier, by template-dependent, nonvascular, cell-to-cell movement," Plant Physiology, vol. 159, no. 3, pp. 984-1000, 2012.

[81] D. S. Skopelitis, A. Y. Husbands, and M. C. Timmermans, "Plant small RNAs as morphogens," Current Opinion in Cell Biology, vol. 24, no. 2, pp. 217-224, 2012.

[82] R. K. Slotkin, M. Vaughn, F. Borges et al., "Epigenetic reprogramming and small RNA silencing of transposable elements in pollen," Cell, vol. 136, no. 3, pp. 461-472, 2009.

[83] M. J. Axtell, C. Jan, R. Rajagopalan, and D. P. Bartel, "A two-hit trigger for siRNA biogenesis in plants," Cell, vol. 127, no. 3, pp. 565-577, 2006.

[84] N. Fahlgren, T. A. Montgomery, M. D. Howell et al., "Regulation of AUXIN RESPONSE FACTOR3 by TAS3 ta-siRNA affects developmental timing and patterning in arabidopsis," Current Biology, vol. 16, no. 9, pp. 939-944, 2006.

[85] L. Williams, C. C. Carles, K. S. Osmont, and J. C. Fletcher, "A database analysis method identifies an endogenous trans-acting short-interfering RNA that targets the Arabidopsis ARF2, ARF3, and ARF4 genes," Proceedings of the National Academy of Sciences of the United States of America, vol. 102, no. 27, pp. 9703-9708, 2005.

[86] F. T. S. Nogueira, A. K. Sarkar, D. H. Chitwood, and M. C. P. Timmermans, "Organ polarity in plants is specified through the opposing activity of two distinct small regulatory RNAs," Cold Spring Harbor Symposia on Quantitative Biology, vol. 71, pp. 157-164, 2006.
[87] L. C. Hsieh, S. I. Lin, A. C. C. Shih et al., "Uncovering small RNA-mediated responses to phosphate deficiency in Arabidopsis by deep sequencing," Plant Physiology, vol. 151, no. 4, pp. 2120-2132, 2009.

[88] R. Rajagopalan, H. Vaucheret, J. Trejo, and D. P. Bartel, "A diverse and evolutionarily fluid set of microRNAs in Arabidopsis thaliana," Genes and Development, vol. 20, no. 24, pp. 3407-3425, 2006.

[89] M. D. Howell, N. Fahlgren, E. J. Chapman et al., "Genome-wide analysis of the RNA-DEPENDENT RNA POLYMERASE6/DICER-LIKE4 pathway in Arabidopsis reveals dependency on miRNA- and tasiRNA-directed targeting," Plant Cell, vol. 19, no. 3, pp. 926-942, 2007.

[90] H. M. Chen, Y. H. Li, and S. H. Wu, "Bioinformatic prediction and experimental validation of a microRNA-directed tandem trans-acting siRNA cascade in Arabidopsis," Proceedings of the National Academy of Sciences of the United States of America, vol. 104, no. 9, pp. 3318-3323, 2007.

[91] D. Windels and F. Vazquez, "miR393: integrator of environmental cues in auxin signaling?" Plant Signaling and Behavior, vol. 6, no. 11, 2011.

[92] A. Si-Ammour, D. Windels, E. Arn-Bouldoires et al., "miR393 and secondary siRNAs regulate expression of the TIR1/AFB2 auxin receptor clade and auxin-related development of arabidopsis leaves," Plant Physiology, vol. 157, no. 2, pp. 683-691, 2011.

[93] P. V. Shivaprasad, H. M. Chen, K. Patel et al., "A microRNA superfamily regulates nucleotide binding site-leucine-rich repeats and other mRNAs," Plant Cell, vol. 24, no. 3, pp. 859-874, 2012.

[94] J. Zhai, D. H. Jeong, E. De Paoli et al., "MicroRNAs as master regulators of the plant NB-LRR defense gene family via the production of phased, trans-acting siRNAs," Genes \& Development, vol. 25, no. 23, pp. 2540-2553, 2011.

[95] F. Li, D. Pignattaa, C. Bendixa et al., "MicroRNA regulation of plant innate immune receptors," Proceedings of the National Academy of Sciences of USA, vol. 109, no. 5, pp. 1790-1795, 2012.

[96] R. Rajeswaran, M. Aregger, A. S. Zvereva et al., "Sequencing of RDR6-dependent double-stranded RNAs reveals novel features of plant siRNA biogenesis," Nucleic Acids Research, vol. 40, no. 13, pp. 6241-6254, 2012.

[97] G. Jagadeeswaran, Y. Zheng, Y. F. Li et al., "Cloning and characterization of small RNAs from Medicago truncatula reveals four novel legume-specific microRNA families," New Phytologist, vol. 184, no. 1, pp. 85-98, 2009.

[98] A. C. Mallory and H. Vaucheret, "ARGONAUTE 1 homeostasis invokes the coordinate action of the microRNA and siRNA pathways," EMBO Reports, vol. 10, no. 5, pp. 521-526, 2009.

[99] A. Carlsbecker, J. Y. Lee, C. J. Roberts et al., "Cell signalling by microRNA165/6 directs gene dose-dependent root cell fate," Nature, vol. 465, no. 7296, pp. 316-321, 2010.

[100] R. Schwab, A. Maizel, V. Ruiz-Ferrer et al., "Endogenous TasiRNAs mediate non-cell autonomous effects on gene regulation in Arabidopsis thaliana," PLoS ONE, vol. 4, no. 6, Article ID e5980, 2009.

[101] F. T. S. Nogueira and M. C. P. Timmermans, "An interplay between small regulatory RNAs patterns leaves," Plant Signaling and Behavior, vol. 2, no. 6, pp. 519-521, 2007.

[102] C. A. Kidner and M. C. P. Timmermans, "Signaling sides. Adaxial-abaxial patterning in leaves," Current Topics in Developmental Biology, vol. 91, pp. 141-168, 2010. 
[103] A. Pulido and P. Laufs, "Co-ordination of developmental processes by small RNAs during leaf development," Journal of Experimental Botany, vol. 61, no. 5, pp. 1277-1291, 2010.

[104] E. Marin, V. Jouannet, A. Herz Aurelie et al., "mir390, Arabidopsis TAS3 tasiRNAs, and their AUXIN RESPONSE FACTOR targets define an autoregulatory network quantitatively regulating lateral root growth," Plant Cell, vol. 22, no. 4, pp. 1104-1117, 2010.

[105] T. A. Montgomery, M. D. Howell, J. T. Cuperus et al., "Specificity of ARGONAUTE7-miR390 interaction and dual functionality in TAS3 trans-acting siRNA formation," Cell, vol. 133, no. 1, pp. 128-141, 2008.

[106] C. Hunter, M. R. Willmann, G. Wu, M. Yoshikawa, M. D. L. L. Gutiérrez-Nava, and R. S. Poethig, "Trans-acting siRNAmediated repression of ETTIN and ARF4 regulates heteroblasty in Arabidopsis," Development, vol. 133, no. 15, pp. 2973-2981, 2006.

[107] P. Dunoyer and O. Voinnet, "Movement of RNA silencing between plant cells: is the question now behind us?" Trends in Plant Science, vol. 14, no. 12, pp. 643-644, 2009.

[108] F. E. Vaistij, L. Jones, and D. C. Baulcombe, "Spreading of RNA targeting and DNA methylation in RNA silencing requires transcription of the target gene and a putative RNA-dependent RNA polymerase," Plant Cell, vol. 14, no. 4, pp. 857-867, 2002.

[109] O. Voinnet, "Use, tolerance and avoidance of amplified RNA silencing by plants," Trends in Plant Science, vol. 13, no. 7, pp. 317-328, 2008.

[110] L. Vermeersch, N. De Winne, and A. Depicker, "Introns reduce transitivity proportionally to their length, suggesting that silencing spreads along the pre-mRNA," Plant Journal, vol. 64, no. 3, pp. 392-401, 2010.

[111] M. Aregger, B. K. Borah, J. Seguin et al., "Primary and secondary siRNAs in geminivirus-induced gene silencing," PLoS Pathog, vol. 8, no. 9, article e1002941, 2012.

[112] E. Allen, Z. Xie, A. M. Gustafson, and J. C. Carrington, "microRNA-directed phasing during trans-acting siRNA biogenesis in plants," Cell, vol. 121, no. 2, pp. 207-221, 2005.

[113] J. T. Cuperus, A. Carbonell, N. Fahlgren et al., "Unique functionality of 22-nt miRNAs in triggering RDR6-dependent siRNA biogenesis from target transcripts in Arabidopsis," Nature Structural and Molecular Biology, vol. 17, no. 8, pp. 997-1003, 2010.

[114] H. M. Chen, L. T. Chen, K. Patel, Y. H. Li, D. C. Baulcombe, and S. H. Wu, "22-Nucleotide RNAs trigger secondary siRNA biogenesis in plants," Proceedings of the National Academy of Sciences of the United States of America, vol. 107, no. 34, pp. 15269-15274, 2010.

[115] R. Schwab and O. Voinnet, "RNA silencing amplification in plants: size matters," Proceedings of the National Academy of Sciences of the United States of America, vol. 107, no. 34, pp. 14945-14946, 2010.

[116] F. F. D. Felippes, F. Ott, and D. Weigel, "Comparative analysis of non-autonomous effects of tasiRNAs and miRNAs in Arabidopsis thaliana," Nucleic Acids Research, vol. 39, no. 7, pp. 2880-2889, 2011.

[117] P. A. Manavella, D. Koenig, and D. Weigel, "Plant secondary siRNA production determined by microRNA-duplex structure," Proceedings of the National Academy of Sciences of the United States of America, vol. 109, no. 7, pp. 2461-2466, 2012.

[118] C. Zhang, G. Li, J. Wang, and J. Fang, "Identification of transacting siRNAs and their regulatory cascades in grapevine," Bioinformatics, vol. 28, no. 20, pp. 2561-2568, 2012.
[119] E. Allen and M. D. Howell, "miRNAs in the biogenesis of trans-acting siRNAs in higher plants," Seminars in Cell and Developmental Biology, vol. 21, no. 8, pp. 798-804, 2010.

[120] T. A. Montgomery, J. Y. Seong, N. Fahlgren et al., "AGO1miR173 complex initiates phased siRNA formation in plants," Proceedings of the National Academy of Sciences of the United States of America, vol. 105, no. 51, pp. 20055-20062, 2008.

[121] D. MacLean, N. Elina, E. R. Havecker, S. B. Heimstaedt, D. J. Studholme, and D. C. Baulcombe, "Evidence for large complex networks of plant short silencing RNAs," PloS One, vol. 5, no. 3, article e9901, 2010.

[122] S. Gazzani, T. Lawrenson, C. Woodward, D. Headon, and R. Sablowski, "A link between mRNA turnover and RNA interference in Arabidopsis," Science, vol. 306, no. 5698, pp. 1046-1048, 2004.

[123] X. Chen, "A silencing safeguard: links between RNA silencing and mRNA processing in arabidopsis," Developmental Cell, vol. 14, no. 6, pp. 811-812, 2008.

[124] B. D. Gregory, R. C. O’Malley, R. Lister et al., "A link between RNA metabolism and silencing affecting arabidopsis development," Developmental Cell, vol. 14, no. 6, pp. 854-866, 2008.

[125] C. Lurin, C. Andrés, S. Aubourg et al., "Genome-wide analysis of arabidopsis pentatricopeptide repeat proteins reveals their essential role in organelle biogenesis," Plant Cell, vol. 16, no. 8, pp. 2089-2103, 2004.

[126] U. Alon, "Network motifs: theory and experimental approaches," Nature Reviews Genetics, vol. 8, no. 6, pp. 450-461, 2007.

[127] O. Shoval and U. Alon, "SnapShot: network motifs," Cell, vol. 143, no. 2, p. 326.e1, 2010.

[128] N. K. Jerne, "The generative grammar of the immune system," Science, vol. 229, no. 4718, pp. 1057-1059, 1985.

[129] S. K. Ekengren, Y. Liu, M. Schiff, S. P. Dinesh-Kumar, and G. B. Martin, "Two MARK cascades, NPR1, and TGA transcription factors play a role in Pto-mediated disease resistance in tomato," Plant Journal, vol. 36, no. 6, pp. 905-917, 2003.

[130] M. L. Dequeant and O. Pourquie, "Segmental patterning of the vertebrate embryonic axis," Nature Reviews Genetics, vol. 9, no. 5, pp. 370-382, 2008.

[131] J. X. Yue, B. C. Meyers, J. Q. Chen et al., “Tracing the origin and evolutionary history of plant nucleotide-binding site-leucinerich repeat (NBS-LRR) genes," New Phytologist, vol. 193, no. 4, pp. 1049-1063, 2012.

[132] R. Medzhitov, "Innate immunity: quo vadis?" Nature Immunology, vol. 11, no. 7, pp. 551-553, 2010. 

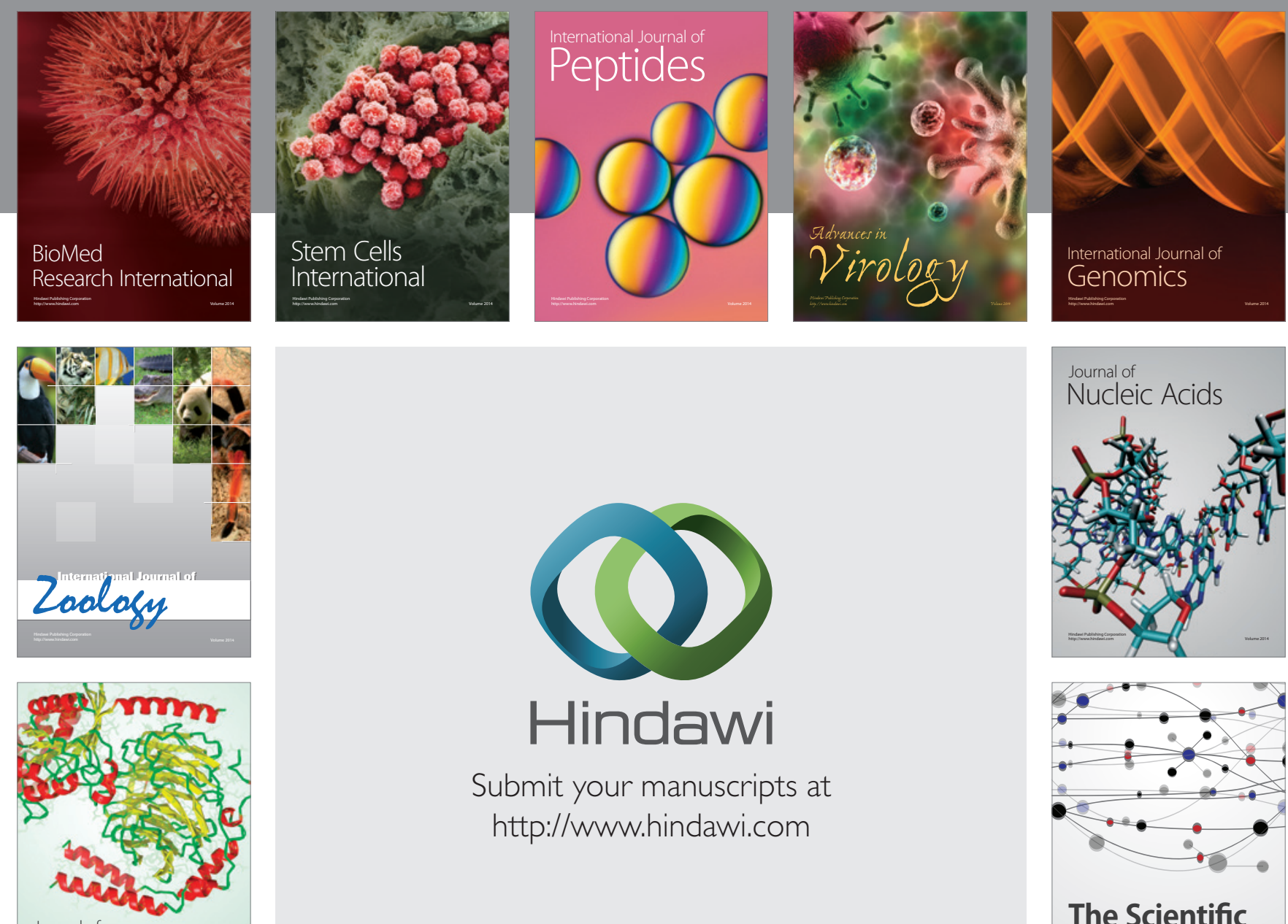

Submit your manuscripts at

http://www.hindawi.com

Journal of
Signal Transduction
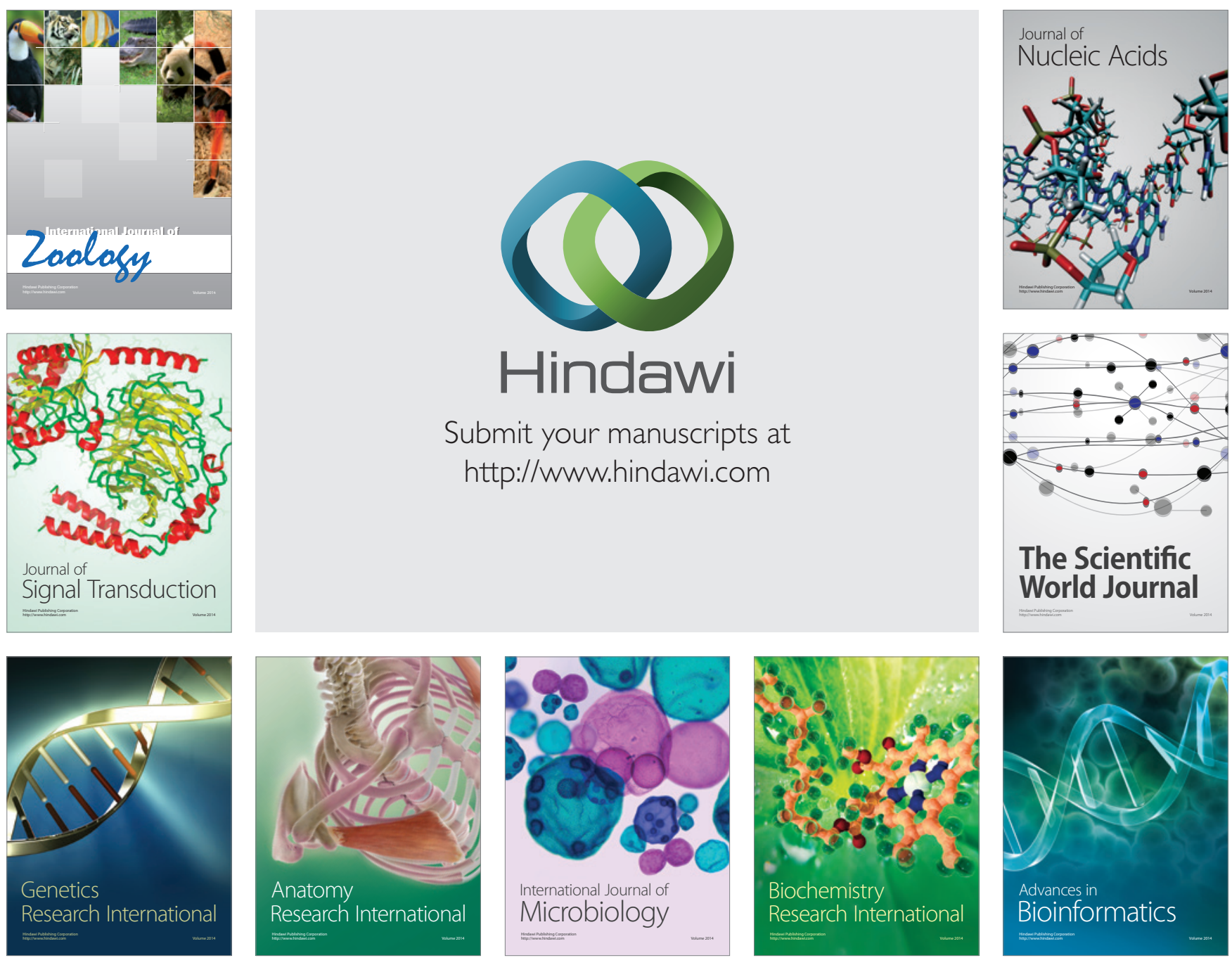

The Scientific World Journal
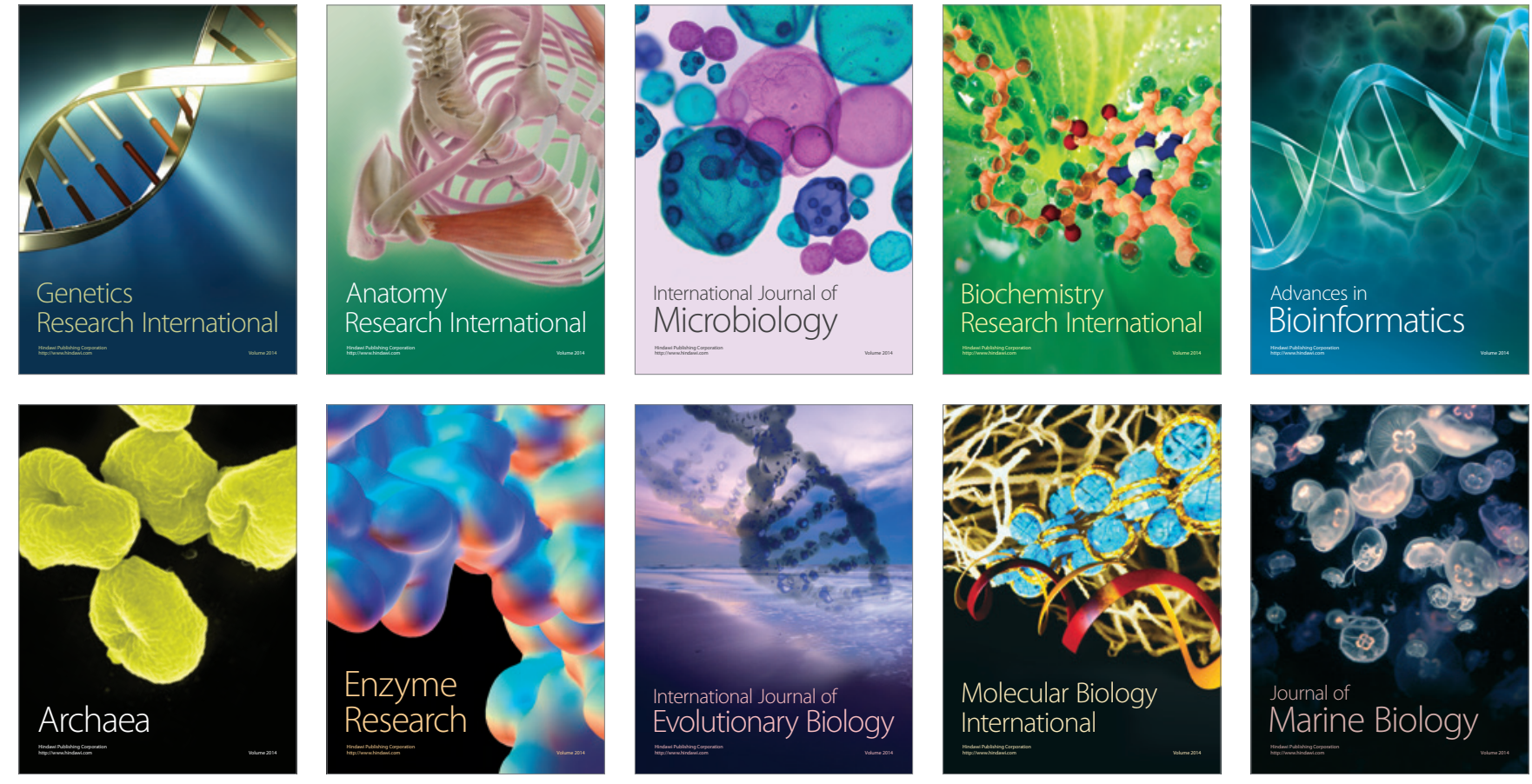